\title{
Bactericidal effects of silver plus titanium dioxide-coated endotracheal tubes on Pseudomonas aeruginosa and Staphylococcus aureus
}

\author{
This article was published in the following Dove Press journal: \\ International Journal of Nanomedicine \\ 12 March 2010 \\ Number of times this article has been viewed
}

\author{
Keiko M Tarquinio' \\ Nikhil K Kothurkar ${ }^{2}$ \\ Dharendra Y Goswami ${ }^{3}$ \\ Ronald C Sanders J $\mathrm{r}^{4}$ \\ Arno L Zaritsky ${ }^{5}$ \\ Ann Marie LeVine ${ }^{6}$ \\ 'Division of Pediatric Critical Care \\ Medicine, Department of Pediatrics, \\ Rhode Island Hospital, The Warren \\ Alpert Medical School, Brown \\ University, Providence, RI USA; \\ ${ }^{2}$ Department of Chemical Engineering \\ and Materials Science, Amrita School \\ of Engineering, Ettimadai, Coimbatore, \\ India; ${ }^{3}$ Clean Energy Research Center, \\ University of South Florida, Tampa, \\ FL, USA; ${ }^{4}$ Section of Pediatric Critical \\ Care, Department of Pediatrics, \\ College of Medicine, University \\ of Arkansas for Medical Sciences, \\ Arkansas Children's Hospital, Little \\ Rock, AR, USA; ${ }^{5}$ Executive Medical \\ Director, Children's Hospital of The \\ King's Daughters, Norfolk, VA, USA; \\ ${ }^{6}$ Pediatric Critical Care Medicine, \\ University of Michigan Medical School, \\ C.S. Mott Children's Hospital, Ann \\ Arbor, MI, USA
}

Correspondence: Keiko Tarquinio Division of Pediatric Critical Care Medicine, Rhode Island Hospital, The Warren Alpert Medical School, Brown University, 593 Eddy St, Potter II5, Providence, RI 02903, USA

Tel + I 40| 444420 I

Fax + I 40I 4445527

Email ktarquinio@lifespan.org
Purpose: Ventilator-associated pneumonia (VAP) is a nosocomial infection resulting in significant morbidity and mortality. Pseudomonas aeruginosa (P. aeruginosa) and Staphylococcus aureus $(S$. aureus) are pathogens associated with VAP. Silver $(\mathrm{Ag})$ coating of endotracheal tubes (ETTs) reduces bacterial colonization, however titanium dioxide $\left(\mathrm{TiO}_{2}\right)$ coating has not been studied.

Methods: Five types of ETT coatings were applied over silica layer: Ag, solgel $\mathrm{TiO}_{2}$, solgel $\mathrm{TiO}_{2}$ with Ag, Degussa P25 $\mathrm{TiO}_{2}$ (Degussa $\mathrm{TiO}_{2}$ ), and Degussa $\mathrm{TiO}_{2}$ with Ag. After ETTs were incubated with $P$. aeruginosa or $S$. aureus; colonization was determined quantitatively.

Results: Pseudomonas aeruginosa and $S$. aureus grew for 5 days on standard ETTs. Compared to standard ETTs, $P$. aeruginosa growth was significantly inhibited by solgel $\mathrm{TiO}_{2}$ with $\mathrm{Ag}$ at 24 hours, and by Degussa $\mathrm{TiO}_{2}$ with $\mathrm{Ag}$ at 24 and 48 hours after inoculation. No significant difference in $S$. aureus growth was observed between the control and any of the five coatings for 5 days.

Conclusion: In vitro, solgel $\mathrm{TiO}_{2}$ with $\mathrm{Ag}$ and Degussa $\mathrm{TiO}_{2}$ with $\mathrm{Ag}$ both attenuated $P$. aeruginosa growth, but demonstrated no effect on $S$. aureus colonization. Further studies using alternative coating and incorporating UV light exposure are needed to identify their potential utility in reducing VAP.

Keywords: ventilator-associated pneumonia, Degussa titanium dioxide, solgel titanium dioxide, quantitative culture

\section{Introduction}

Ventilator-associated pneumonia (VAP) is one of the most common nosocomial infections among intensive care unit patients, which prolongs ventilation and hospitalization, resulting in significant morbidity, mortality and medical costs. ${ }^{1-3}$ Researchers have developed strategies to prevent VAP, including controlling gastric $\mathrm{pH}$, intratracheal intubation with a high-pressure endotracheal tube (ETT) cuff, continuous subglottic suction to prevent microaspiration, promoting oral hygiene with chlorhexidine, and semi-recumbent positioning. ${ }^{4-9}$

One strategy to reduce VAP is to treat the ETT with an antiseptic agent to control ETT biofilm formation. ${ }^{10,11} \mathrm{~A}$ biofilm is an aggregate of a bacterial community attached to a solid surface and encased in an exopolysaccharide matrix, making it resistant to antibiotic penetration. ${ }^{12}$ Biofilm formation is most prominent in the distal third of the ETT and can occur as early as sixty hours following endotracheal intubation. ${ }^{13}$ 
Due to silver's antimicrobial properties, Pacheco-Fowler and colleagues studied chlorhexidine and $\mathrm{Ag}$ carbonate impregnated ETTs in an in vitro model and observed that bacterial growth of $S$. aureus, $P$. aeruginosa, and other organisms was attenuated. ${ }^{14}$ Similarly, Rello et al found that bacterial colonization was delayed for seven days in adults intubated with Ag-coated ETTs compared with standard ETTs ${ }^{15}$ and Kollef and colleagues concluded a statistically significant reduction in the VAP incidence in a randomized multicenter trial. ${ }^{16}$

Titanium dioxide is widely used as an antimicrobial agent, but it is not commonly employed in the medical setting. In a process known as photocatalysis, $\mathrm{TiO}_{2}$ is activated into potent oxidative species when exposed to UV light, with antiviral, antibacterial as well as fungicidal actions. ${ }^{17}$ Recent, investigations have suggested that the photocatalytic activity is important in destroying a range of bacteria including $S$. aureus and $P$. aeruginosa in aqueous solutions. ${ }^{18}$ Photocatalytic activity also is implicated in the inhibition of biofilm formation on $\mathrm{TiO}_{2}$ based dental implants. ${ }^{19,20} \mathrm{In}$ view of these antimicrobial actions it is plausible that $\mathrm{TiO}_{2}-$ coating of ETTs, potentially in combination with UV light, may sterilize ETTs in patients' airways, thereby reducing the risk of VAP.

We conducted a pilot study of bacterial growth behavior on $\mathrm{TiO}_{2}$-coated ETTs without UV exposure to evaluate the antimicrobial effect of $\mathrm{TiO}_{2}$ on polyvinyl chloride (PVC) which is used to manufacture ETTs. Initial experiments examined $\mathrm{TiO}_{2}$ without UV light exposure for two reasons. First, the $\mathrm{Ag}$ and $\mathrm{TiO}_{2}$ combination has not been studied on PVC material. Second, if the Ag and $\mathrm{TiO}_{2}$ coating has antimicrobial activity without photocatalysis, this would reduce potential toxicity from UV exposure. The objective of this study was to determine if $\mathrm{TiO}_{2}$-coated ETTs with or without $\mathrm{Ag}$ would reduce bacterial colonization by two common VAP pathogens (ie, $P$. aeruginosa or $S$. aureus) in an in vitro model compared with standard ETTs.

\section{Material and methods}

\section{Solgel $\mathrm{TiO}_{2}$ synthesis}

Sols of $\mathrm{TiO}_{2}$ were made using a method adapted from Mills and colleagues. ${ }^{21} \mathrm{~A}$ solution of $10 \mathrm{~mL}$ titanium isopropoxide (AC19470 98+\%; Acros Organics, Geel, Belgium) in $2.32 \mathrm{~g}$ glacial acetic acid (A465-250; Fisher Chemical, Pittsburgh, PA), was stirred into $60 \mathrm{~mL}$ deionized water acidified with $0.59 \mathrm{~g}$ concentrated nitric acid (S719721; Fisher Chemical). The reaction solution was then heated rapidly and held at $80^{\circ} \mathrm{C}$ for 8 hours. The solution was concentrated by heating at $150^{\circ} \mathrm{C}$ to $11 \mathrm{wt} \% \mathrm{TiO}_{2}$ followed by dilution with ethanol (AC61510; Acros Organics) to obtain a translucent white sol containing $6 \mathrm{wt} \% \mathrm{TiO}_{2}$ sol.

\section{Endotracheal tubes}

The inner lumens of the ETTs were first coated with silica $\left(\mathrm{SiO}_{2}\right)$ which served as a passivating layer to prevent the $\mathrm{TiO}_{2}$ from degrading the polyvinyl chloride (PVC) and to improve surface wettability by the subsequently applied $\mathrm{TiO}_{2}$ coatings. The $\mathrm{SiO}_{2}$ layer was applied using a nebulizer spray of $15 \mathrm{wt} \%$ colloidal $\mathrm{SiO}_{2}$ in deionized water through the ETT, through a custom-designed nozzle, for 1 minute with an air flow rate of 10 liters per minute. The ETT was then dried with $85^{\circ} \mathrm{C}$ air for 1 minute.

The respective $\mathrm{TiO}_{2}$ and $\mathrm{Ag}$ treatments are summarized in Table 1. Five types of coatings were applied over the $\mathrm{SiO}_{2}$ layer (Figure 1): 1) solgel $\mathrm{TiO}_{2}, 2$ ) solgel $\mathrm{TiO}_{2}$ with $\mathrm{Ag}$, 3) Degussa $\mathrm{TiO}_{2}$ (Evonik Degussa, Parsippany, NJ, USA), 4) Degussa $\mathrm{TiO}_{2}$ with Ag, and 5) Ag (not shown in Figure 1). Each of the coating solutions A-D had $0.19 \mathrm{wt} \% \mathrm{TiO}_{2}$ on a dry weight basis. Water and ethanol were used as solvents in variable ratios for each solution. Solgel $\mathrm{TiO}_{2}$ was used for solutions $\mathrm{A}$ and $\mathrm{B}$, while $\mathrm{C}$ and $\mathrm{D}$ solutions consisted of solgel and Degussa $\mathrm{TiO}_{2}$ in the ratio 20:80 wt/wt. Silver nitrate $\left(\mathrm{AgNO}_{3}\right)$ was added to solutions $\mathrm{B}$ and $\mathrm{D}$. For solution $\mathrm{E}, \mathrm{AgNO}_{3} 0.1 \mathrm{wt} \%$ was mixed in ethanol-water (50:50 $\mathrm{wt} / \mathrm{wt}$ ). Two types of $\mathrm{TiO}_{2}$ coatings were applied; solgel

Table I Coating solutions with their respective titanium dioxide and silver treatments

\begin{tabular}{lllll}
\hline Tube & Solution & $\mathrm{TiO}_{2}$ source & Solvent & $\mathbf{A g N O}_{3}: \mathrm{TiO}_{2}\left(\mathbf{m o l}^{2}\right)$ \\
\hline I & $\mathrm{A}$ & Solgel & Water: Ethanol (60:40) & 0 \\
2 & $\mathrm{~B}$ & Solgel & Water: Ethanol (60:40) & 5.6 \\
3 & $\mathrm{C}$ & Solgel: Degussa $(20: 80)$ & Water: Ethanol (3:97) & 0 \\
4 & $\mathrm{D}$ & Solgel: Degussa (20:80) & Water: Ethanol (5:95) & 5.6 \\
5 & $\mathrm{E}$ & $\mathrm{NoTiO}_{2}$ & Water: Ethanol (50:50) & $0.1 \mathrm{wt} \% \mathrm{AgNO}_{3}$ \\
\hline
\end{tabular}

Abbreviations: $\mathrm{Ag}$, silver; $\mathrm{AgNO}_{3}$, silver nitrate; Degussa $\mathrm{TiO}_{2}$, Degussa $\mathrm{P} 25$ titanium dioxide; $\mathrm{TiO}_{2}$, titanium dioxide. 


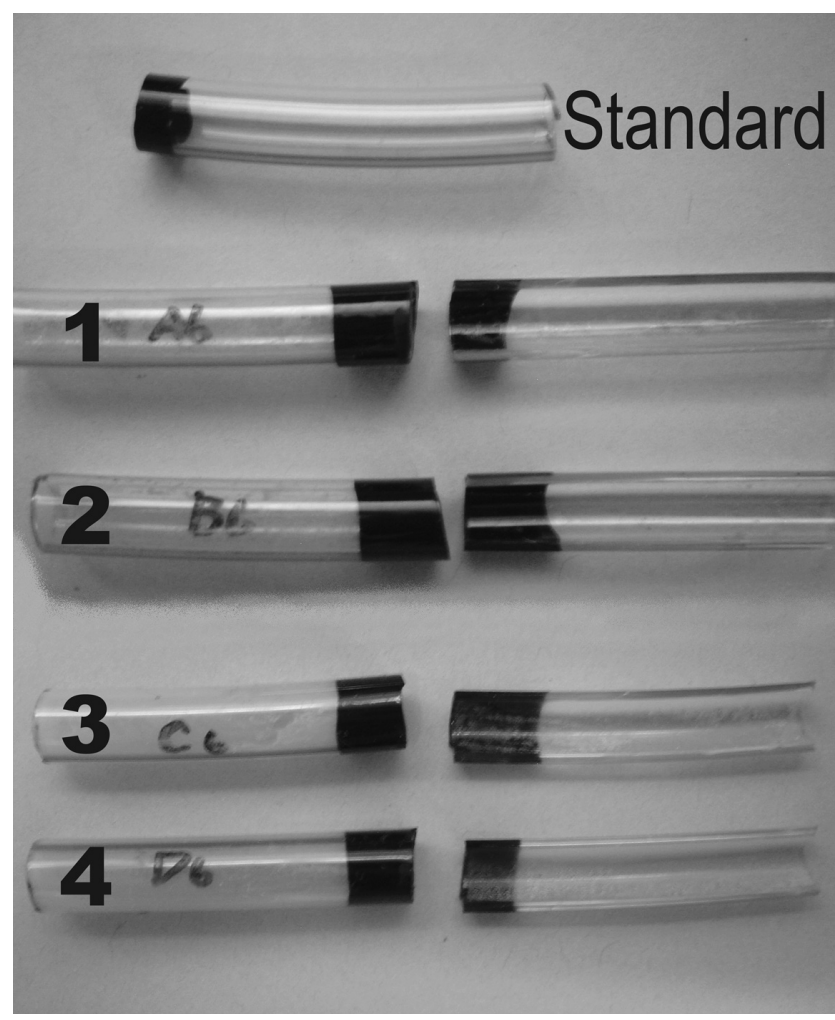

Figure I Standard endotracheal tubes were coated with a passivating layer of colloidal silica and served as controls. Five types of coatings were applied over a silica layer; I. solgel titanium dioxide without silver, 2 . solgel titanium dioxide with silver, 3 . Degussa titanium dioxide without silver, 4. Degussa titanium dioxide with silver and 5. silver only (not shown).

to increase adherence to PVC for substrate depositition and Degussa $\mathrm{TiO}_{2}$ for potentially high photocatalytic performance. Since Degussa $\mathrm{TiO}_{2}$ suspensions had very poor adhesion to the ETTs, they were mixed with a small amount of sols of solgel $\mathrm{TiO}_{2}$. After $\mathrm{TiO}_{2}$ coating, the ETTs were dried with $85^{\circ} \mathrm{C}$ air for 1 minute, followed by further drying in an air-circulating oven at $100^{\circ} \mathrm{C}$ for 15 minutes, then packed while warm.

\section{Preparation of $P$. aeruginosa}

Freeze-dried P. aeruginosa (ATCC \#25668; American Type Culture Collection, Manassas, VA, USA) was rehydrated with nutrient broth in aliquots to be stored at $-80^{\circ} \mathrm{C}$. After a loopful of frozen bacteria was plated and incubated, a single colony was inoculated into $4 \mathrm{~mL}$ tryptic soy broth (TSB) and incubated overnight at $37^{\circ} \mathrm{C}$. The following day, the turbid bacterial broth was vortexed and inoculated. To determine the exact inoculums, $100 \mu \mathrm{L}$ of bacterial broth was serially diluted with phosphate-buffered saline (PBS), then optical density was measured to obtain $10^{8}$ colony forming units/milliliter (CFU/mL).

\section{Preparation of S. aureus}

Frozen $S$. aureus (ATCC \#25923) was rehydrated with TSB in the same fashion as $P$. aeruginosa, and stored at $-80^{\circ} \mathrm{C}$. Frozen $S$. aureus was inoculated into $50 \mathrm{~mL}$ TSB in a flask, and incubated overnight at $37^{\circ} \mathrm{C}$. Turbid $S$. aureus bacterial broth was transferred to a $50 \mathrm{~mL}$ sterile culture tube, centrifuged for 15 minutes, and the supernatant was discarded. A concentrated broth was made by the addition of $1 \mathrm{~mL}$ of TSB to the pellet of $S$. aureus. Optical density was measured to obtain $10^{9} \mathrm{CFU} / \mathrm{mL}$ for ETT inoculation.

\section{Bacterial inoculation of ETTs}

Each ETT was marked at $4 \mathrm{~cm}$ intervals for later division into six equal pieces, then immersed in $75 \%$ alcohol for 15 minutes to sterilize, rinsed with $20 \mathrm{~mL} 0.9 \%$ sterile saline, and air dried. After sterilization, each ETT was cut into six pieces, sealed on one end with Tegaderm ${ }^{\circledR}$ (3M, St. Paul, $\mathrm{MN}$ ), filled with either $8 \mu \mathrm{l}$ of $P$. aeruginosa broth plus $800 \mu \mathrm{l}$ TSB or $100 \mu \mathrm{l}$. aureus broth plus $700 \mu \mathrm{l}$ TSB, then sealed with Tegaderm. All ETT pieces were placed in a 2 liter dry flask and agitated at $37^{\circ} \mathrm{C}$ overnight. On the following day, the bacterial fluid was drained from each ETT piece.

\section{Peroxidase assay after coating ETTs}

Colorimetric measurement was used to detect whether $\mathrm{TiO}_{2}$ on ETTs generated peroxidase as part its antimicrobial property. EM Quant Peroxide Test Strips (EMD Chemicals Inc. Gibbstown, NJ, USA) which measure peroxidase between 1-100 parts-per million were used. Trypic soy broth $800 \mu \mathrm{L}$ was placed on the $\mathrm{TiO}_{2}$-coated ETT for 24 hours at $37^{\circ} \mathrm{C}$ in the dark. Following incubation, the colorimetric strip was dipped into the TSB and the value of peroxidase production was determined.

\section{Observation of bacterial growth}

Bacterial inoculated ETT pieces were placed in an incubator to simulate the in vitro human trachea with no ambient light, a relative humidity of $>90 \%$, temperature of $37^{\circ} \mathrm{C}$ and at standard atmospheric pressure. Bacterial growth was observed for 24, 48, 72, 96, 120, and 144 hours after inoculation on the standard and five test ETTs. The inner surface of bacteria was collected by washing with $0.5 \mathrm{~mL}$ of sterile PBS and swabbing every 24 hours after inoculation. The collected fluid was serially diluted and plated on tryptic soy agar for incubation overnight at $37^{\circ} \mathrm{C}$. Colony counts were expressed as $\mathrm{CFU} / \mathrm{mL}$, and each experiment was repeated four times. 


\section{Statistical analysis}

Data were reported as mean \pm standard error of mean (SEM). Bacterial colony counts were analyzed using Mann-Whitney $U$ test comparing coated ETTs with standard ETTs. A $P$-value of $<0.05$ was considered statistically significant.

\section{Results}

The coating was slightly opaque using solgel $\mathrm{TiO}_{2}$ compared with Degussa $\mathrm{TiO}_{2}$. Samples with Ag-containing coatings appeared dark due to the reduction of $\mathrm{AgNO}_{3}$ to $\mathrm{Ag}$. The coating was particulate in appearance to the naked eye and peeled off while collecting the bacteria by mechanical force. Peroxidase production was not detected on $\mathrm{TiO}_{2}$-coated ETTs.

\section{Pseudomonas aeruginosa}

Growth peaked at 72 hours and continued for 144 hours on standard ETTs. Pseudomonas aeruginosa growth was more robust on Ag-coated ETTs compared to standard ETTs at 120 hours $(P=0.04)$ and 144 hours $(P=0.06)$ despite initial slow growth in the first 24 hours (Figure 2). There was no difference in $P$. aeruginosa growth over 144 hours among standard, solgel $\mathrm{TiO}_{2}$ and Degussa $\mathrm{TiO}_{2}$-coated ETTs (Figure 3). Compared to standard ETTs, solgel $\mathrm{TiO}_{2}$ with $\mathrm{Ag}$ inhibited

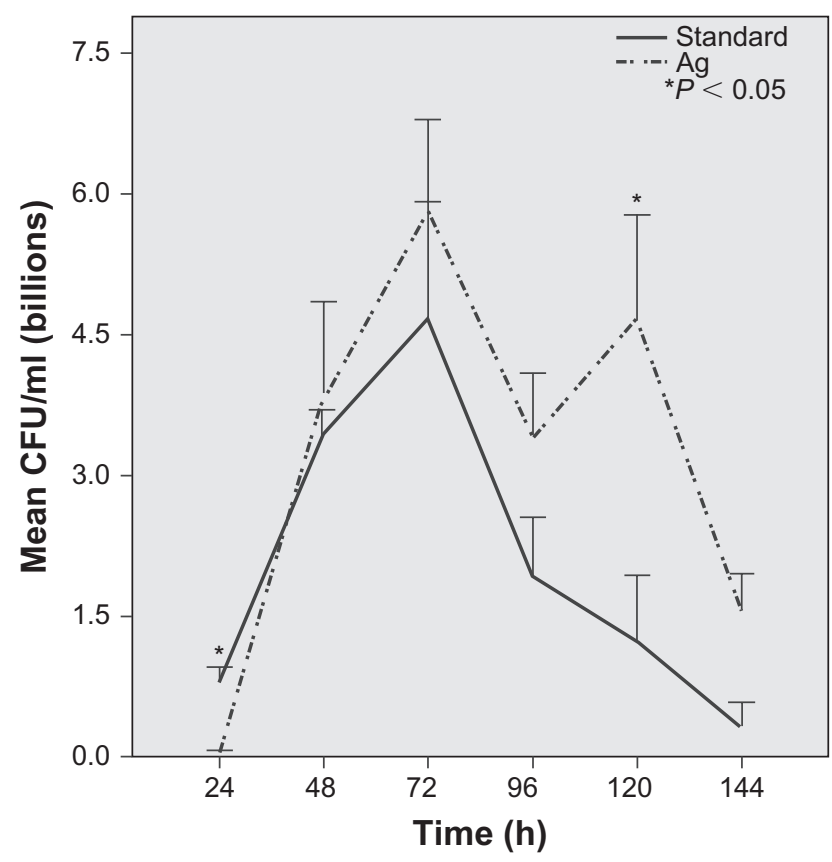

Figure 2 Characterization of $P$. aeruginosa growth on polyvinyl chloride endotracheal tubes over a 144-hour period. Comparison of standard and silver only coated endotracheal tubes. There was less $P$. aeruginosa growth on silver-coated endotracheal tubes at 24 hours $(P<0.01)$, but more growth at I 20 hours $(P=0.04)$ and I 44 hours $(P=0.06)$ compared to standard endotracheal tubes.

Notes: Mean \pm standard error of mean, ${ }^{*} P<0.05$ compared to standard endotracheal tube. $\mathrm{N}=4$.

Abbreviation: $\mathrm{CFU}$, colony-forming units.

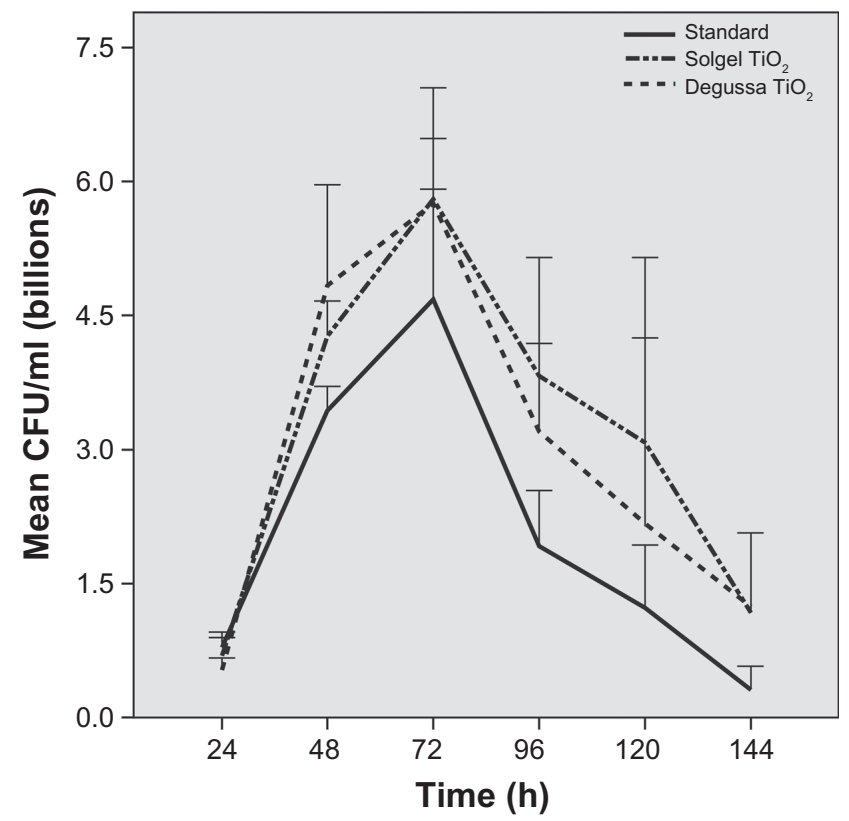

Figure 3 Characterization of $P$. aeruginosa growth on polyvinyl chloride endotracheal tubes coated with titanium dioxide over I44 hour period. Comparison of standard, solgel titanium dioxide and Degussa titanium dioxide endotracheal tubes. $P$. aeruginosa growth was not statistically significant at all time points.

Notes: Mean \pm standard error of mean, $\mathrm{N}=4$.

Abbreviation: $\mathrm{CFU}$, colony-forming units.

$P$. aeruginosa growth at 24 hours $(P=0.02)$, and Degussa $\mathrm{TiO}_{2}$ with Ag inhibited $P$. aeruginosa growth at 24 and 48 hours after inoculation ( $P=0.02$ and $P=0.02$, respectively) (Figure 4).

\section{Staphylococcus aureus}

Growth was observed up to 144 hours. Staphylococcus aureus growth peaked at 48 hours after inoculation on both standard and Ag-coated ETTs without a difference over 144 hours (Figure 5). Furthermore, there was also no difference in $S$. aureus growth over 144 hours between standard, solgel $\mathrm{TiO}_{2}$ and Degussa $\mathrm{TiO}_{2}$-coated ETTs (Figure 6). Compared to standard ETTs, neither solgel $\mathrm{TiO}_{2}$ with $\mathrm{Ag}$ nor Degussa $\mathrm{TiO}_{2}$ with Ag showed a difference in S. aureus growth over a 144 hour period except solgel $\mathrm{TiO}_{2}$ with $\mathrm{Ag}$ at the 144 hour point after inoculation in which there was a significant attenuation of S. aureus growth compared to the standard ETT (Figure 7).

\section{Discussion}

Clinically, VAP is diagnosed after patients have been mechanically ventilated for more than 48 hours similar to the duration of bacterial growth in our simulated model. The growth of $P$. aeruginosa was consistent with the findings of other investigators under comparable conditions when monitoring growth in the first 24 hours. ${ }^{22,23}$ An initial suppression of $P$. aeruginosa in Ag-coated ETT was also 


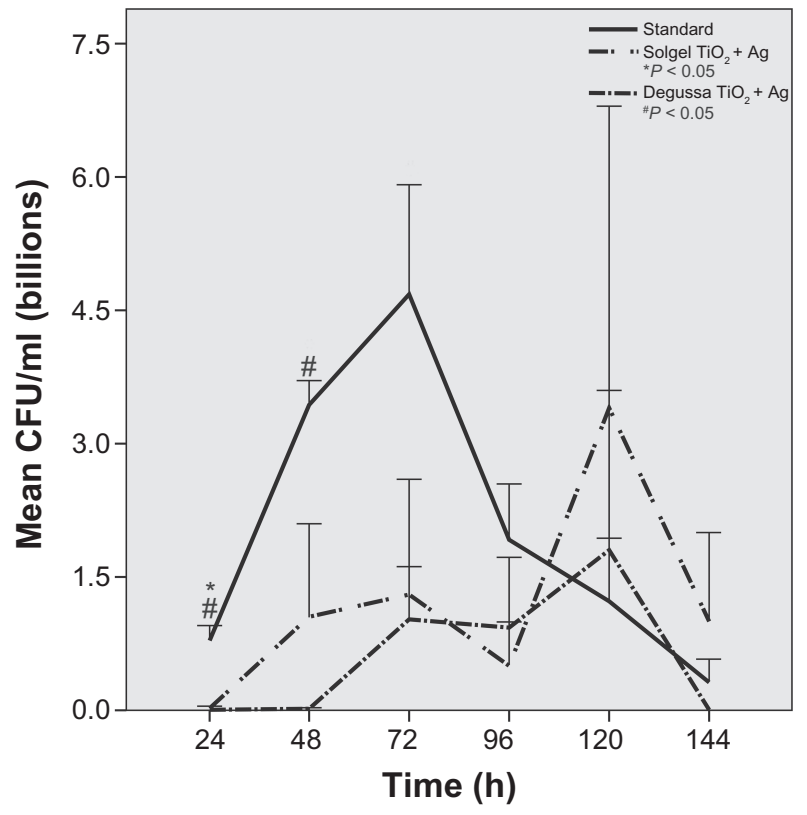

Figure 4 Characterization of $P$. aeruginosa growth on polyvinyl chloride endotracheal tubes coated with titanium dioxide with silver over a 144-hour period. Comparison of standard, solgel titanium dioxide with silver, and Degussa titanium dioxide with silver endotracheal tubes. $P$. aeruginosa growth was inhibited significantly by solgel titanium dioxide with silver at 24 hours and by Degussa titanium dioxide with silver at 24 and 48 hours, respectively.

Notes: Mean \pm standard error of mean; $* P<0.05$ compared to standard endotracheal tube, $\# P<0.05$ compared to standard endotracheal tube. $N=4$.

Abbreviation: CFU, colony-forming units.

observed in sections of intraventricular tubing impregnated with Ag. ${ }^{23}$ Moreover, our experience was similar to results of others who observed an undulating pattern of bacterial growth over a 50 hour period in Ag-coated ETTs. ${ }^{24}$ The second $P$. aeruginosa growth peak observed in Figure 2 was thought to be an experimental variation due to the small sample size.

A similar growth pattern on Ag-coated ETT was also observed in a study evaluating the growth of $P$. aeruginosa and $S$. aureus on PVC even in the presence of antimicrobials. Both $P$. aeruginosa and $S$. aureus produce a biofilm; its robustness is strain dependent. ${ }^{25-27}$ Biofilm generating species of $S$. aureus exhibit accelerating growth kinetics in the first 6 days in animal models. Furthermore, these strains form microcolonies on catheter substrates that serve as sites of biofilm formation. ${ }^{28}$ Thus, it is likely that $S$. aureus growth was probably blunted in our model until a glycocalyx developed, then growth proceeded in the presence of nutrients and favorable conditions.

The antimicrobial properties of $\mathrm{Ag}$ result from $\mathrm{Ag}$ ions binding to bacterial sulphydryl- or histidyl-containing proteins, which disrupt transmembranous energy metabolism and electrolyte transport systems. ${ }^{29}$ Because the cell wall composition and thickness vary between gram positive and gram negative bacteria, silver's antimicrobial effect may be

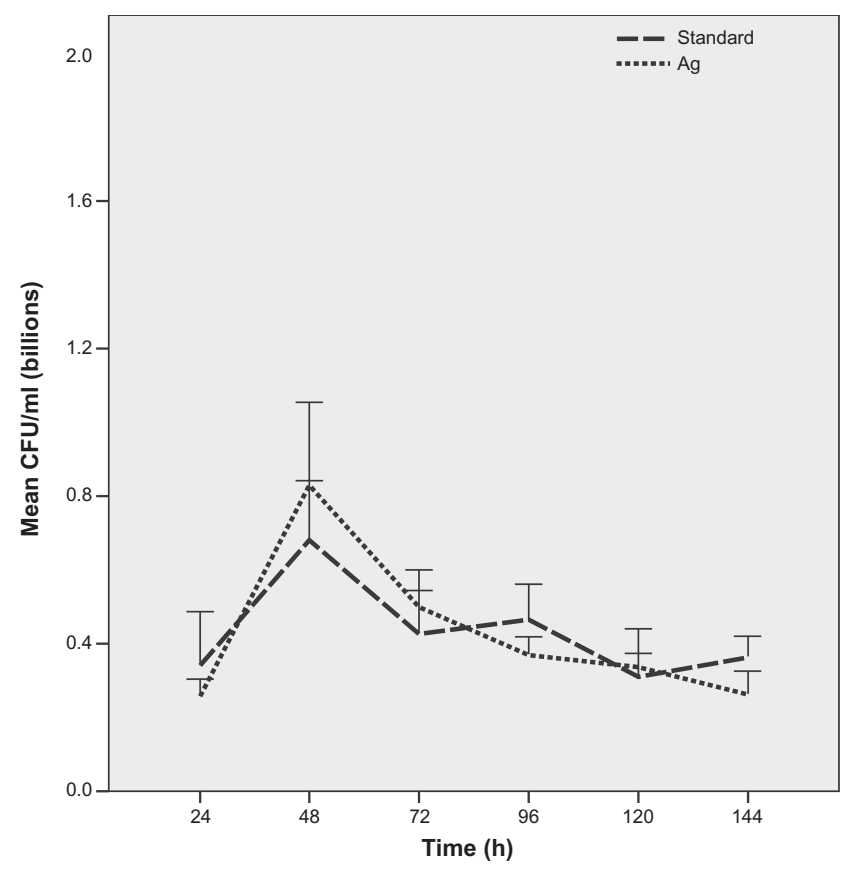

Figure 5 Characterization of S. aureus growth on polyvinyl chloride endotracheal tubes coated with silver only over a I44-hour period. Comparison of standard and silver only coated endotracheal tubes. There was no difference in S. aureus growth between standard and silver coated endotracheal tubes at any time point over I44 hours compared with standard endotracheal tubes.

Note: $\mathrm{N}=4$.

Abbreviation: $\mathrm{CFU}$, colony-forming units.

greater in $P$. aerugionsa than in $S$. aureus during the initial phase of bacterial multiplication.

The characteristics of discolored Ag-coated particles were not analyzed in this experiment. However, $\mathrm{AgNO}_{3}$ is known to undergo photochemical reduction to metallic $\mathrm{Ag}$ upon exposure to light as described by the reaction:

$$
2 \mathrm{AgNO}_{3} \rightarrow 2 \mathrm{Ag}+2 \mathrm{NO}_{2}+\mathrm{O}_{2}
$$

This leads to the tiny particles precipitation of $\mathrm{Ag}$ that appears black or brown. Future studies are needed to define the specific mechanism involved in the antimicrobial properties of Ag as well as the physiological impact of discolored Ag. Silver nitrate was not expected to react with $\mathrm{SiO}_{2}$ under ambient conditions, since $\mathrm{SiO}_{2}$ is quite nonreactive.

Application and treatment of ETTs with these chemicals may also change the surface charge and hydrophobicity, as in this study, thus changing the PVC characteristics from hydrophobic to hydrophilic.

This study demonstrated that the addition of $\mathrm{TiO}_{2}$ significantly augmented the antibacterial effects of $\mathrm{Ag}$ on $P$. aeruginosa during the first 72 hours, but had no effect on S. aureus. In our limited study, $\mathrm{TiO}_{2}$ photocatalysis was not observed as determined by the release of hydrogen peroxide 


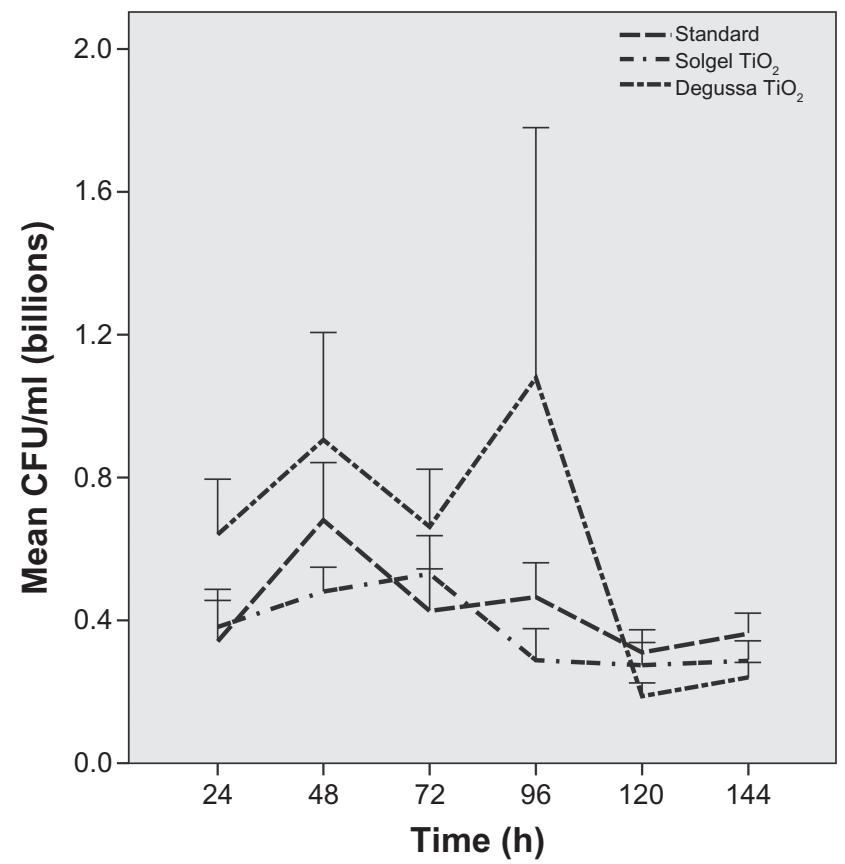

Figure 6 Characterization of S. aureus growth on polyvinyl chloride endotracheal tubes coated with titanium dioxide only over a 144-hour period. Comparison of standard, solgel titanium dioxide and Degussa titanium dioxide endotracheal tubes. There was no difference in S. aureus growth in the titanium dioxide-coated groups compared to standard endotracheal tubes at any time point.

Note: $\mathrm{N}=4$.

Abbreviation: $\mathrm{CFU}$, colony-forming units.

as a part of reactive oxygen species. Silver and $\mathrm{TiO}_{2}$ might have reacted with each other releasing $\mathrm{Ag}$ ion, and this reactant might have a synergistic antimicrobial effect even in a dark environment without photocatalysis.

In contrast, Yao showed that application of thin films of $\mathrm{Ag}$ and $\mathrm{TiO}_{2}$ for sterilization purposes on silicone catheters promptly eliminates $S$. aureus within 90 minutes without $\mathrm{TiO}_{2}$-photocatalysis. They also showed inhibition of growth of Escherichia coli (E. coli) and P. aeruginosa, although they only observed growth for 24 hours. ${ }^{30} \mathrm{Li}$ and colleagues demonstrated that $\mathrm{AgNO}_{3}$ and $\mathrm{TiO}_{2}$ pulverized to surgical masks reduced E. coli and $S$. aureus by $100 \%$. In Li's study, Ag plus $\mathrm{TiO}_{2}$ pulverized masks were exposed to UV-C irradiation prior to bacterial inoculation. ${ }^{31}$ Pseudomonas aeruginosa behaves very differently in the initial phase of bacterial attachment to the surface compared to S. aureus. Rogers and colleagues demonstrated that S. aureus multiplies and produces a biofilm on the surface that thickens monotonically, becoming hard during growth and softening during starvation. In comparison, $P$. aeruginosa showed much less reproducible behavior; the organism was loosely adhered and detached from the surface after several hours in vitro. ${ }^{32}$ Until $P$. aerugionosa attachment is established,

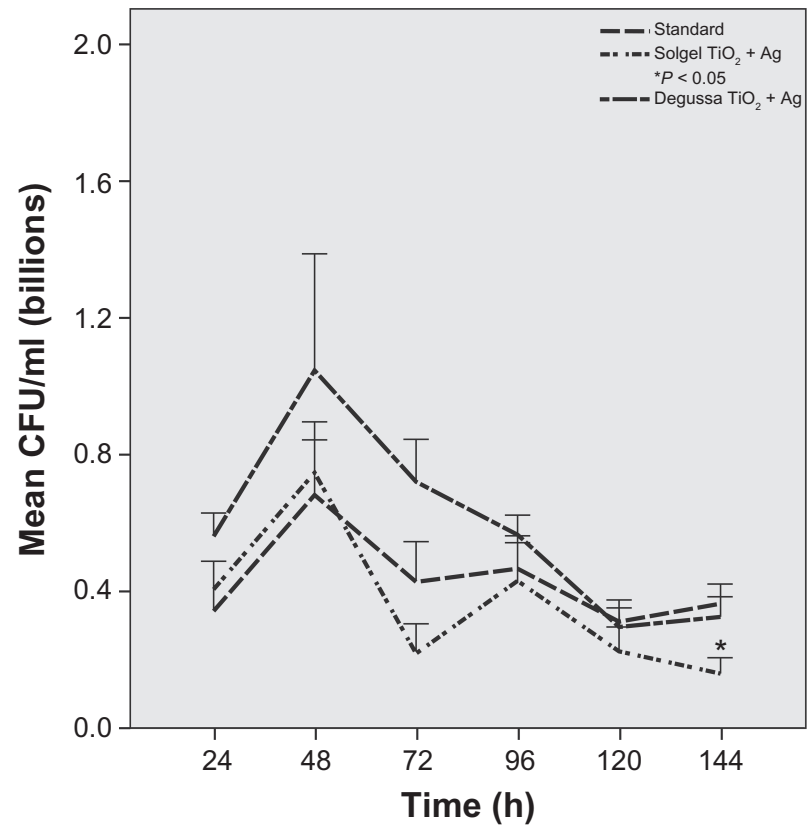

Figure 7 Characterization of S. aureus growth on polyvinyl chloride endotracheal tubes coated with titanium dioxide with silver over a 144-hour period. Comparison of standard, solgel titanium dioxide with silver and Degussa titanium dioxide with silver endotracheal tubes. There was no difference in S. aureus growth in the titanium dioxide with silver-coated groups compared to standard endotracheal tubes except at I 44 hours with solgel titanium dioxide with silver endotracheal tubes. Note: $\mathrm{N}=4$.

Abbreviation: CFU, colony-forming units.

this initial motile motion phase may be inhibited or delayed by synergistic bactericidal activity of $\mathrm{Ag}$ and either form of $\mathrm{TiO}_{2}$ as we demonstrated.

Our study has several limitations. First, it was conducted in an in vitro model that was designed to replicate the human tracheal environment. However, the results may not be applicable to the in vivo setting where other factors may impact the ETT surface such as frequent suctioning, nebulizer therapy or host factors. Second, the concomitant use of Ag and $\mathrm{TiO}_{2}$ would seem to be marginally effective against VAP if it does not inhibit a common cause of VAP (ie, S. aureus). Third, minimizing the particulate surface that facilitates bacterial binding could be effective by reducing the surface area for bacterial adherence and growth. Fourth, the coating, peeled off under mechanical stress, could be dislodged by a suction catheter and produce potentially harmful Ag particles in the human airway and lung parenchyma. Nevertheless, titanium dioxide is known to be safe in humans and is used in such products as cosmetics, toothpaste, and sun screen. Hence, the combination of $\mathrm{Ag}$ and $\mathrm{TiO}_{2}$ needs to be evaluated in a clinical setting. Lastly, this study did not directly evaluate the attractive feature of $\mathrm{TiO}_{2}$ photocatalysis. The potency of $\mathrm{TiO}_{2}$ either individually or in combination with $\mathrm{Ag}$ needs to 
be examined in conjunction with photocatalysis. However, exposing tracheal mucosa to UV light involves potential toxicity. This potential risk and, more importantly, its clinical feasibility, need to be ascertained in future studies.

\section{Conclusion}

One strategy to reduce the incidence of VAP is to pretreat ETT with an antiseptic agent to reduce or delay bacterial biofilm formation. The use of $\mathrm{TiO}_{2}$ with Ag-coated ETTs effectively inhibited $P$. aeruginosa growth, but not $S$. aureus growth, in an in vitro model of a human trachea environment.

\section{Disclosures}

The authors have no conflicts of interest to disclose in this work.

\section{References}

1. Chastre J, Fagon JY. Ventilator-associated pneumonia. Am J Respir Crit Care Med. 2002;165:867-903.

2. Elward AM, Warren DK, Fraser VJ. Ventilator-associated pneumonia in pediatric intensive care unit patients: risk factors and outcomes. Pediatrics. 2002;109:758-764.

3. Warren DK, Shukla SJ, Olsen MA, et al. Outcome and attributable cost of ventilator-associated pneumonia among intensive care unit patients in a suburban medical center. Crit Care Med. 2003;31:1312-1317.

4. Cook D, Reeve B, Guyatt G, et al. Stress ulcer prophylaxis in critically ill patients. Resolving discordant meta-analyses. JAMA. 1996;275:308-314.

5. Crnich C, Safdar N, Maki D. The role of the intensive care unit environment in the pathogenesis and prevention of ventilator-associated pneumonia. Respir Care. 2005;50:813-836; discussion, 836-818.

6. Rello J, Sonora R, Jubert P, et al. Pneumonia in intubated patients: role of respiratory airway care. Am J Respir Crit Care Med. 1996;154:111-115.

7. Gujadhur R, Helme BW, Sanni A, et al. Continuous subglottic suction is effective for prevention of ventilator associated pneumonia. Interact Cardiovasc Thorac Surg. 2005;4:110-115.

8. DeRiso AJ 2nd, Ladowski JS, Dillon TA, et al. Chlorhexidine gluconate $0.12 \%$ oral rinse reduces the incidence of total nosocomial respiratory infection and nonprophylactic systemic antibiotic use in patients undergoing heart surgery. Chest. 1996;109:1556-1561.

9. Drakulovic MB, Torres A, Bauer TT, et al. Supine body position as a risk factor for nosocomial pneumonia in mechanically ventilated patients: a randomised trial. Lancet. 1999;354:1851-1858.

10. Adair CG, Gorman SP, Byers LM, et al. Eradication of endotracheal tube biofilm by nebulised gentamicin. Intensive Care Med. 2002;28:426-431.

11. Safdar N, Crnich C, Maki D. The pathogenesis of ventilator-associated pneumonia: its relevance to developing effective strategies for prevention. Respir Care. 2005;50:725-739; discussion, 739-741.

12. Costerton JW, Stewart PS, Greenberg EP. Bacterial biofilms: a common cause of persistent infections. Science. 1999;284:1318-1322.
13. Feldman C, Kassel M, Cantrell J, et al. The presence and sequence of endotracheal tube colonization in patients undergoing mechanical ventilation. Eur Respir J. 1999;13:546-551.

14. Pacheco-Fowler V, Gaonkar T, Wyer PC, et al. Antiseptic impregnated endotracheal tubes for the prevention of bacterial colonization. J Hosp Infect. 2004;57:170-174.

15. Rello J, Kollef M, Diaz E, et al. Reduced burden of bacterial airway colonization with a novel silver-coated endotracheal tube in a randomized multiple-center feasibility study. Crit Care Med. 2006;34:2766-2772.

16. Kollef MH, Afessa B, Anzueto A, et al. Silver-coated endotracheal tubes and incidence of ventilator-associated pneumonia: the NASCENT randomized trial. JAMA. 2008;300:805-813.

17. Fujishima A. TiO2 Photocatalysis: Fundamentals and applications. Tokyo, Japan: BKC, Inc; 1999.

18. Tsuang YH, Sun JS, Huang YC, et al. Studies of photokilling of bacteria using titanium dioxide nanoparticles. Artif Organs. 2008;32:167-174.

19. Arai T, Ueda T, Sugiyama T, et al. Inhibiting microbial adhesion to denture base acrylic resin by titanium dioxide coating. J Oral Rehabil. 2009;36:902-908.

20. Veltri M, Ferrari M, Balleri P. Stability values of titanium dioxideblasted dental implants in edentulous maxillas: a 3-year pilot study. J Oral Rehabil. 2009 Nov 4. [Epub ahead of print].

21. Mills A, Elliott N, Hill G, et al. Preparation and characterisation of novel thick sol-gel titania film photocatalysts. Photochem Photobiol Sci. 2003;2:591-596.

22. Ramstedt M, Houriet R, Mossialos D, et al. Wet chemical silver treatment of endotracheal tubes to produce antibacterial surfaces. $J$ Biomed Mater Res B Appl Biomater. 2007;83:169-180.

23. Secer HI, Kural C, Kaplan M, et al. Comparison of the efficacies of antibiotic-impregnated and silver-impregnated ventricular catheters on the prevention of infections. An in vitro laboratory study. Pediatr Neurosurg. 2008;44:444-447.

24. Hartmann M, Guttmann J, Muller B, et al. Reduction of the bacterial load by the silver-coated endotracheal tube (SCET), a laboratory investigation. Technol Health Care. 1999;7:359-370.

25. Otto M. Staphylococcal biofilms. Curr Top Microbiol Immunol. 2008;322:207-228.

26. Corrigan RM, Rigby D, Handley P, et al. The role of Staphylococcus aureus surface protein SasG in adherence and biofilm formation. Microbiology. 2007;153:2435-2446.

27. Gotz F. Staphylococcus and biofilms. Mol Microbiol. 2002;43:1367-1378.

28. Fluckiger U, Ulrich M, Steinhuber A, et al. Biofilm formation, icaADBC transcription, and polysaccharide intercellular adhesin synthesis by staphylococci in a device-related infection model. Infect Immun. 2005;73:1811-1819.

29. Guggenbichler JP, Boswald M, Lugauer S, et al. A new technology of microdispersed silver in polyurethane induces antimicrobial activity in central venous catheters. Infection. 1999;27(Suppl 1):S16-S23.

30. Yao Y, Ohko Y, Sekiguchi Y, et al. Self-sterilization using silicone catheters coated with $\mathrm{Ag}$ and $\mathrm{TiO}_{2}$ nanocomposite thin film. $J$ Biomed Mater Res B Appl Biomater. 2008;85:453-460.

31. Li Y, Leung P, Yao L, et al. Antimicrobial effect of surgical masks coated with nanoparticles. J Hosp Infect. 2006;62:58-63.

32. Rogers SS, van der Walle C, Waigh TA. Microrheology of bacterial biofilms in vitro: Staphylococcus aureus and Pseudomonas aeruginosa. Langmuir. 2008;24:13549-13555.
International Journal of Nanomedicine

\section{Publish your work in this journal}

The International Journal of Nanomedicine is an international, peerreviewed journal focusing on the application of nanotechnology in diagnostics, therapeutics, and drug delivery systems throughout the biomedical field. This journal is indexed on PubMed Central, MedLine, CAS, SciSearch ${ }^{\circledR}$, Current Contents ${ }^{\circledR} /$ Clinical Medicine,

\section{Dovepress}

Journal Citation Reports/Science Edition, EMBase, Scopus and the Elsevier Bibliographic databases. The manuscript management system is completely online and includes a very quick and fair peer-review system, which is all easy to use. Visit http://www.dovepress.com/ testimonials.php to read real quotes from published authors. 